\title{
Analysis of multiband graphene-based terahertz square-ring fractal antenna
}

\author{
Zinelabiddine Mezache \\ Institute of Optics and Fine Mechanics, University of Ferhat Abbas Setif 1, Setif \\ 19000, Algeria. zinemezaache@yahoo.fr
}

Received: 21.02 .2020

\begin{abstract}
A new terahertz square-ring patch antenna is designed basing on a very thin layer of graphene as a radiating patch. It is characterized by multiband operation and can improve the radiation pattern due to its self-similar property or fractal geometry. We analyze a graphene-based square-ring patch placed upon a silicon substrate with the thickness $3.25 \mu \mathrm{m}$. The structure has compact dimensions and radiates at a single frequency, $3.62 \mathrm{THz}$. Our antenna can also consist of a microstrip line to resonate at two $(1.913$ and $4.294 \mathrm{THz})$ or three $(1.913,3.167$ and $4.260 \mathrm{THz})$ frequencies. This is achieved by varying the patch shape at the voltage standing-wave ratio less or equal to two. Our calculations are performed using a fullwave electromagnetic simulation based on a standard finite-difference time domain method. Various parameters like the return loss, the voltage standing-wave ratio, the gain and the efficiency are determined for the multiband operation regime.
\end{abstract}

Keywords: square ring, fractals, multiband resonance, graphene, terahertz antenna, finite-difference time domain method.

UDC: $535,537.5$

\section{Introduction}

Graphene represents a 2D arrangement of single layers of carbon atoms organized in a structure like a honeycomb $[1,2]$. Recently, a progress in terahertz-frequency technologies has stipulated rapid evolution of applications associated with LAN or PANS networks. However, terahertz range of communications is still somewhat problematic due to high path losses at high operating frequencies. Consequently, miniaturization is a prerequisite for improving terahertz devices [311]. Although planar microstrip antennas are well suited for this purpose, scaling down of metal antennas to a micrometer range would result in severe attenuation, low gain and very low efficiency due to low carrier mobility. These limits of metallic antennas can be eliminated due to graphene as a radiating source. Indeed, graphene has a very high carrier mobility which is equal to about $8000 \div 10000 \mathrm{~cm}^{2} \mathrm{~V}^{-1} \mathrm{~s}^{-1}$ and can even reach $200000 \mathrm{~cm}^{2} \mathrm{~V}^{-1} \mathrm{~s}^{-1}$ at the room temperature [5]. As a result, many researchers have been developing graphene-based terahertz antennas [3-11].

Multiband antennas are important for cognitive and multiservice radios, while integration of a large number of bands into a single antenna proves to be essential for various applications. Graphene-based single- or dual-band terahertz antennas have already been discussed in the literature [4-6]. For instance, a silicon (the dielectric permittivity $\varepsilon_{r}=11.9$ ) substrate with the thickness $45 \mu \mathrm{m}$ makes the antenna resonate at two bands [4]. Single- and dual-band regimes are attained using two different materials, e.g. Teflon (the dielectric permittivity $\varepsilon_{r}=2.1$ ) and silicon, combined at a single substrate layer [5]. Moreover, the authors of Ref. [6] have introduced graphene antenna arrays to provide multiband operation, although this approach results in a bulky structure.

Ukr. J. Phys. Opt. 2020, Volume 21, Issue 2 
In the present study, a patch with fractal square-ring geometry and a thin $(3.25 \mu \mathrm{m})$ silicon substrate are used to provide the antenna resonances at two or three frequency bands with good enough performance characteristics. This new strategy improves the antennas and offers their multiband behaviour via fractal geometry, thus yielding in miniaturization and wider bandwidth due to a self-similarity and space-filling property of the underlying structure. Moreover, adding more functionality under conditions of three frequency bands can potentially lead to novel solutions in telecommunications. Summarizing our results, we have introduced a new class of miniaturized terahertz-range patch antennas by employing square-ring fractal geometry and designed a model of multiband graphene-based terahertz antenna with a good radiation pattern. We apply finite-difference time domain approach to simulate and model our terahertz square-ring patch antenna. Since all the frequency bands are well adapted, there is a demand: all the values of the reflection coefficient in these bands at the input $\left(S_{11}\right)$ should be lower than $-10 \mathrm{~dB}$.

\section{Electronic model of graphene}

Graphene can be modelled in two regimes, linear and nonlinear ones. A linear model of graphene is described basing on a known Kubo formula [3-11]. The surface conductivity of graphene consists of two parts originating from the carrier intraband transition $\left(\sigma_{\text {int ra }}\right)$ and the interband transition $\left(\sigma_{\text {inter }}\right)$ [2-4]. A graphene sheet is modelled as an infinitesimally thin metal, using a 2D tensor surface conductivity, $\sigma_{\text {total }}=\sigma_{\text {int ra }}+\sigma_{\text {inter }}$. Due to Pauli's blocking effect, the interband conductivity can be neglected at lower terahertz frequencies, and the total conductivity of graphene is influenced by the intraband contribution only [2-4]. The surface conductivity of graphene is calculated by the Kubo's formula $[3,4]$. In numerical simulations, graphene is usually represented as a layer of material with the Drude-like intraband contribution $[3,4]$

$$
\sigma_{\text {intra }}(\omega)=\frac{2 e^{2} k_{\mathbf{B}} T i}{\pi \hbar^{2}\left(\omega+i \tau^{-1}\right)} \ln \left[2 \cosh \left[\frac{\mu_{c}}{2 k_{\mathbf{B}} T}\right]\right] .
$$

The interband contribution reads as

$$
\sigma_{\text {inter }}(\omega)=\frac{e^{2}}{4 \hbar}\left[H\left(\frac{\omega}{2}\right)+i \frac{4 \omega}{\pi} \int_{0}^{\infty} \frac{H(\varepsilon)-H\left(\frac{\omega}{2}\right)}{\omega^{2}-4 \varepsilon^{2}} d \varepsilon\right],
$$

where $H$ is the Heaviside step function. Here the abbreviation

$$
H(\varepsilon)=\frac{\sinh \left[\frac{\hbar \varepsilon}{k_{\mathbf{B}} T}\right]}{\cosh \left[\frac{\mu_{c}}{k_{\mathbf{B}} T}\right]+\cosh \left[\frac{\hbar \varepsilon}{k_{\mathbf{B}} T}\right]}
$$

is introduced, where $e$ denotes the electron charge, $k_{B}$ the Boltzmann constant, $T$ the temperature, $\hbar$ the reduced Plank's constant, $\mu_{c}$ the chemical potential, $\tau$ the relaxation time, $\omega$ the frequency, and $\varepsilon$ the energy of the band. The absorption cross section (see Fig. 1) is defined by the ratio of the dissipated power to the incident power, so that one obtains

$$
\sigma_{a b s}=\frac{\oint_{S} d^{2} r S \cdot n}{\left|S_{i n c}\right|},
$$

where $n$ stands for the normal to the surface, and $S$ and $S_{i n c}$ are respectively the Poynting vectors of the total and incident fields. 


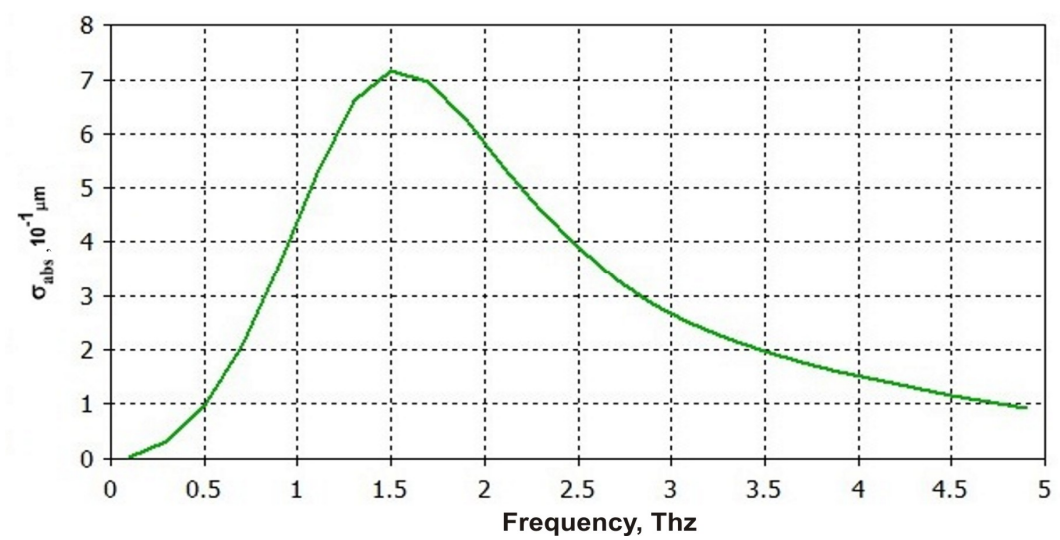

Fig. 1. Absorption cross section obtained for a graphene model with the parameters $W=10 \mu \mathrm{m}, L=10 \mu \mathrm{m}$, $\tau=0.1 \mathrm{ps}$ and $\mu_{c}=0 \mathrm{eV}$ (see Fig. 3 for definition of geometrical parameters). The temperature is equal to $T=300 \mathrm{~K}$.

\section{Antenna designs}

The square-ring geometry can be provided using iteration procedure with the characteristics of self-similar geometric structures [12]. According to this optimization, one takes the structure shown in Fig. 2 as a starting point, of which shape is being changed. This increases the number of resonance frequencies. The structure selected by us is made up of graphene. The latter is placed on a silicon substrate layer. In its turn, the silicon layer is deposited on a layer of graphene plan of mass (see Fig. 3). Then the resonant frequency is given by

$$
f_{r}=\frac{c}{2(L+\Delta L) \sqrt{\varepsilon_{r e f f}}} .
$$

The width $W$ and the length $L$ of the patch read as

$$
W=\frac{c}{2 f_{r}}\left(\frac{\varepsilon_{r}+1}{2}\right)^{-0.5}
$$

and

$$
L=\left(\frac{c}{2 f_{r} \sqrt{\varepsilon_{\text {reff }}}}\right)-2 \Delta L .
$$

Here $\Delta L$ is the extension in patch length that accounts for the fringing fields:

$$
\Delta L=0.412 h \frac{\left(\varepsilon_{\text {reff }}+0.3\right)((W / h)+0.264)}{\left(\varepsilon_{\text {reff }}-0.258\right)((W / h)+0.8)}
$$

where $c$ is the velocity of light, $h$ the substrate height and $\varepsilon_{\text {reff }}$ the effective dielectric constant of the substrate.

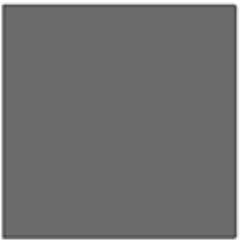

Iteration 0

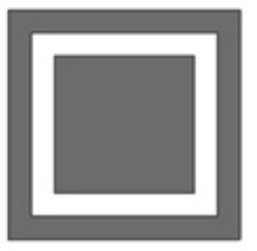

Iteration 1

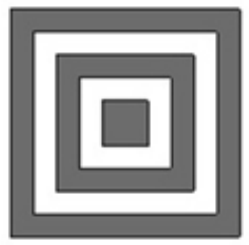

Iteration 2

Fig. 2. Successive iterations of structure of a square-ring graphene-based patch antenna. 


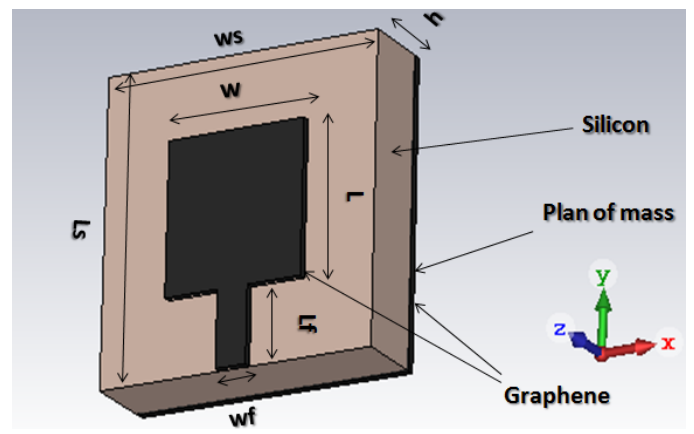

Fig. 3. Graphene-based fractal square-ring patch antenna (zero order).

Fig. 3, Fig. 4 and Fig. 5 illustrate the geometries and designs of our graphene-based patch antennas, while Table 1 provides the corresponding dimensions.

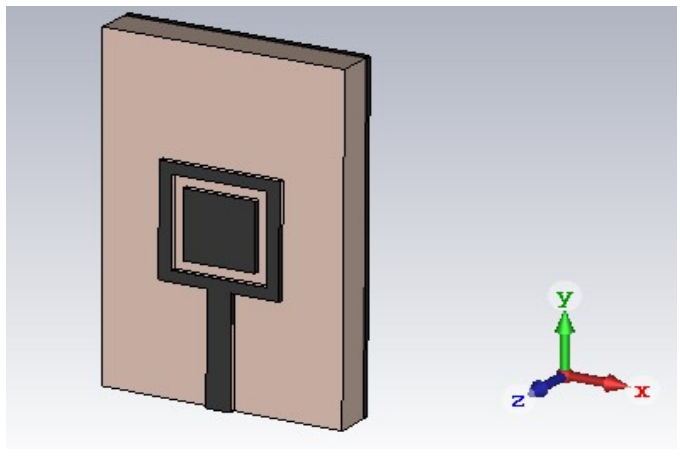

Fig. 4. Graphene-based fractal square-ring patch antenna (first order).

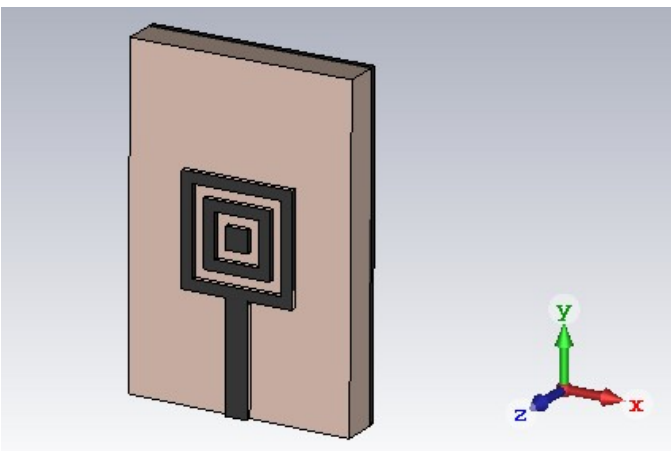

Fig. 5. Graphene-based fractal square-ring patch antenna (second order).

Table 1. Geometric parameters of our graphene-based patch antenna.

\begin{tabular}{ll}
\hline Parameter & Dimension, $\mu \mathrm{m}$ \\
\hline Patch length $L$ & 10 \\
Patch width $W$ & 10 \\
Substrate length $L s$ & 30 \\
Substrate width $W s$ & 20 \\
Substrate height $h$ & 3.25 \\
Microstrip feed length $L f$ & 10 \\
Microstrip feed width $W f$ & 2 \\
\hline
\end{tabular}

\section{Results and discussion}

The axes in Fig. 3, Fig. 4 and Fig. 5 indicate directional orientation of our antennas. Their working frequencies are as follows. At the zero iteration for the square-ring patch, a single band is obtained at $3.62 \mathrm{THz}$, with the return loss $-12.25 \mathrm{~dB}$. For the case of first iteration, we have a dual-band regime, with 1.913 and $4.294 \mathrm{THz}$, and the return losses -42.18 and $-23.35 \mathrm{~dB}$, respectively. Finally, the second iteration yields in the antenna resonances located at $1.913,3.167$ and $4.260 \mathrm{THz}$. Then the return losses amount respectively to $-33.7,-17.72$ and $-18.59 \mathrm{~dB}$.

We notice that the frequency dependence of $S_{11}$ (see Fig. 6) suggests a significant number of resonance frequencies. Moreover, this number increases with increasing number of the rings. In particular, one can see that the antenna corresponding to the second iteration indeed combines three resonance frequencies. This structure reveals also a significant directivity property. 


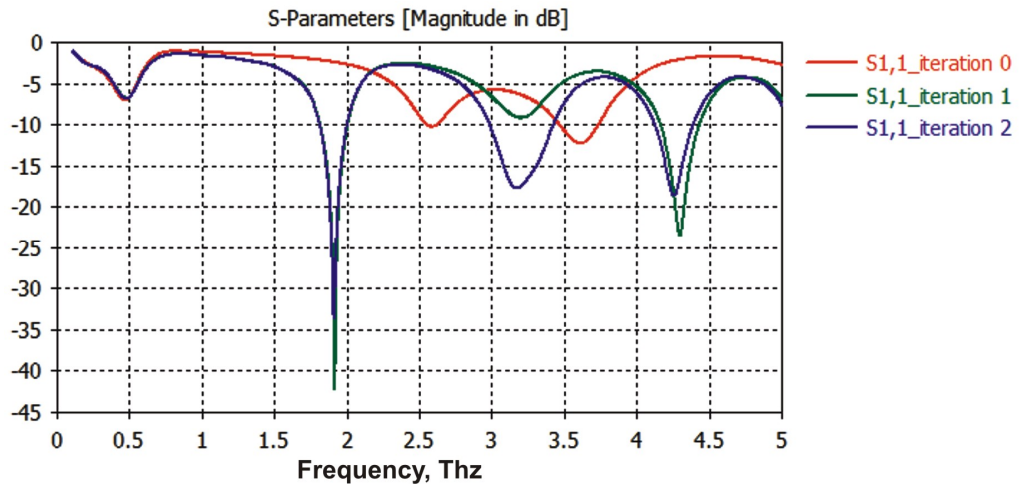

Fig. 6. Frequency dependences of $S_{11}$ parameter for our graphene-based patch antennas.

Let us analyze this property in a more detail. 3D radiation patterns for the zero-order structure are displayed in Fig. 7, along with the patterns specific for the E-plane and H-plane. It is evident that the antenna radiates mainly along the $\mathrm{Z}$ direction, with a very good radiation pattern. Moreover, the data for the zero-order antenna in the E-plane (i.e., the plane $Y-Z$ ) at $\Phi=90^{\circ}$ is very important. One can note that the antenna radiates exactly along the $Z$ direction, with a very small back lobe, $-5.4 \mathrm{~dB}$. The main lobe along the $\mathrm{Z}$ direction has the angular width $92.5^{\circ}$.
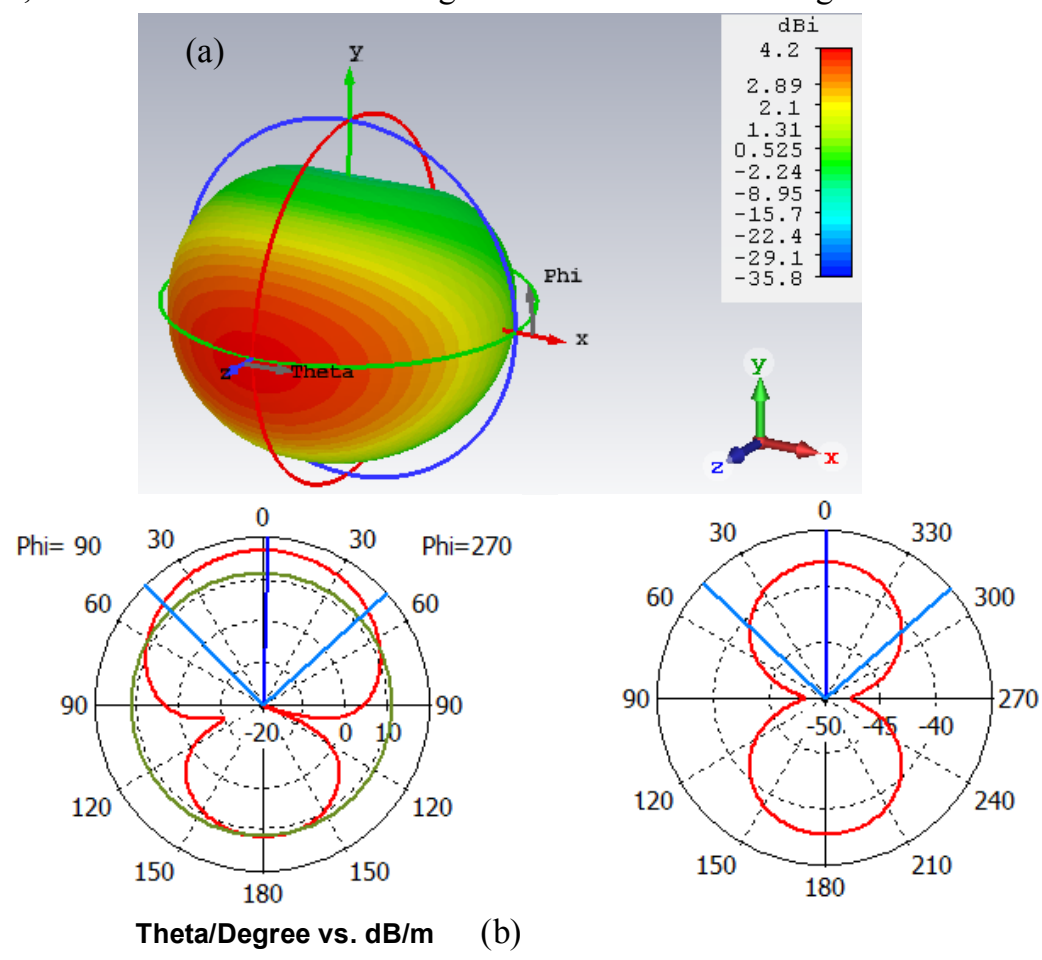

(b)

Fig. 7. General 3D radiation pattern observed for the zero-order structure at $3.620 \mathrm{THz}(\mathrm{a})$, and its cross sections by the E-plane $\left(\Phi=90^{\circ}\right)$ and $\mathrm{H}$-plane $\left(\theta=90^{\circ}\right)(\mathrm{b})$.

Fig. 8 and Fig. 9 give the radiation patterns for the first-order structure in the E- and H-planes. This antenna also radiates mainly along the $\mathrm{Z}$ direction, again revealing a good radiation pattern. The results obtained for the E-plane $\left(\Phi=90^{\circ}\right)$ testify that the antenna radiates exactly along the $Z$ direction. The back lobes $(-3.1 \mathrm{~dB}$ at $1.913 \mathrm{THz}$ and $-5.6 \mathrm{~dB}$ at $4.294 \mathrm{THz})$ are small enough. The angular widths of the main lobe observed along the $\mathrm{Z}$ direction are equal to $104.6^{\circ}$ at $1.913 \mathrm{THz}$ and $91.8^{\circ}$ at $4.294 \mathrm{THz}$.

Ukr. J. Phys. Opt. 2020, Volume 21, Issue 2 

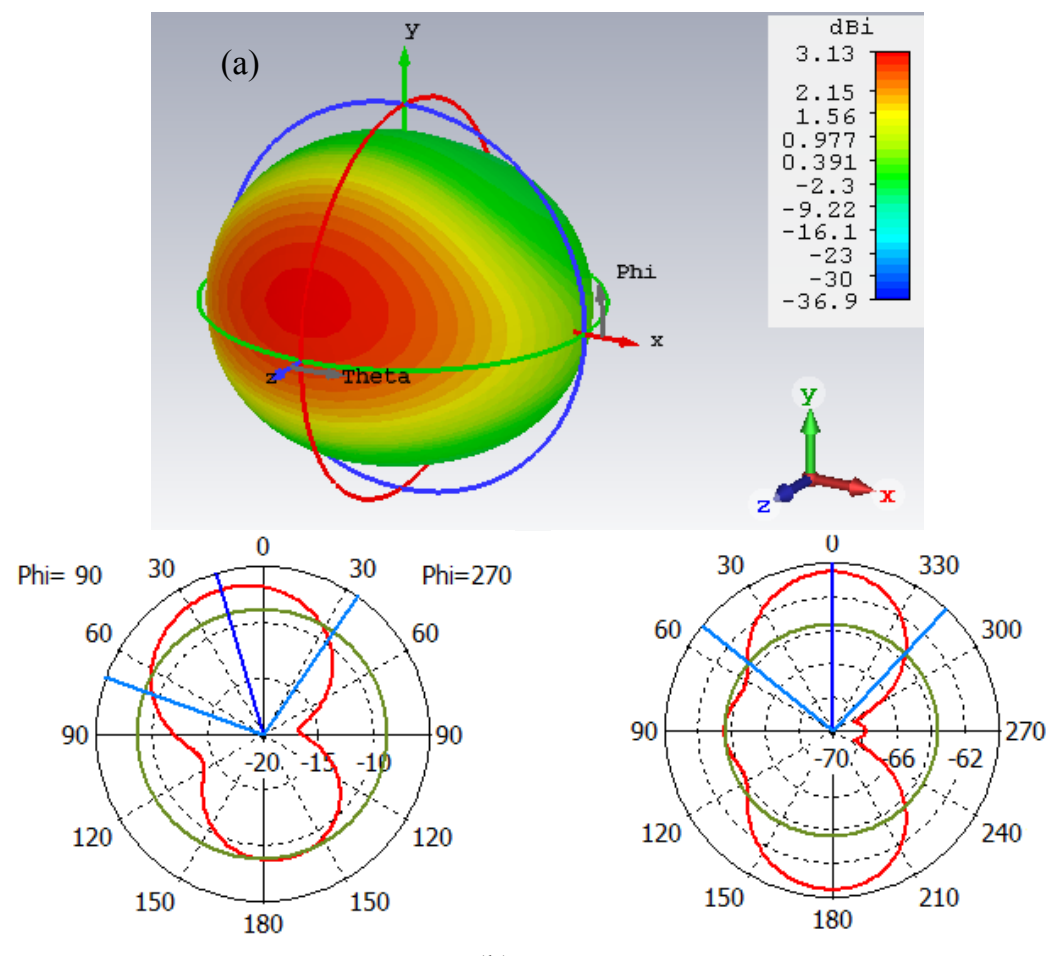

Theta/Degree vs. $\mathrm{dB} / \mathrm{m} \quad$ (b)

Fig. 8. General 3D radiation pattern observed for the first-order structure at $1.913 \mathrm{THz}(\mathrm{a})$, and its cross sections by the E-plane $\left(\Phi=90^{\circ}\right)$ and $\mathrm{H}$-plane $\left(\theta=90^{\circ}\right)(\mathrm{b})$.
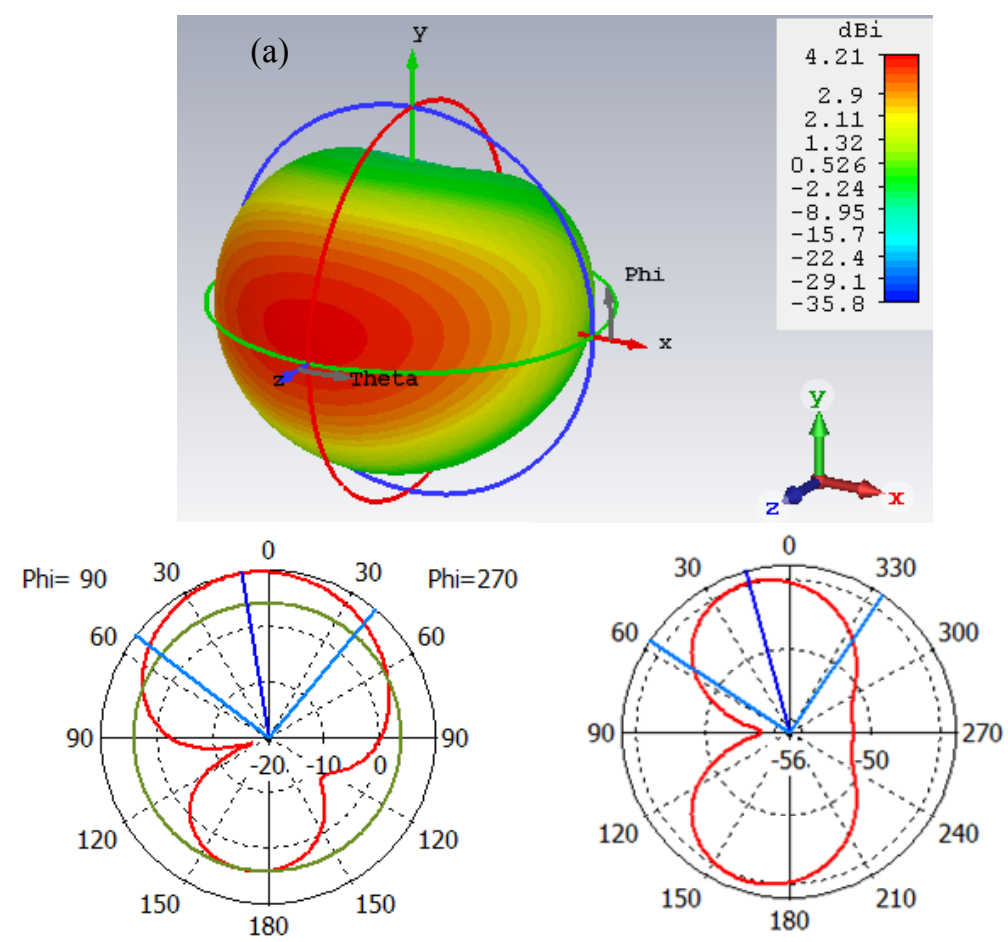

Theta/Degree vs. $\mathrm{dB} / \mathrm{m} \quad$ (b)

Fig. 9. General 3D radiation pattern observed for the first-order structure at $4.294 \mathrm{THz}(\mathrm{a})$, and its cross sections by the E-plane $\left(\Phi=90^{\circ}\right)$ and $\mathrm{H}$-plane $\left(\theta=90^{\circ}\right)(\mathrm{b})$. 

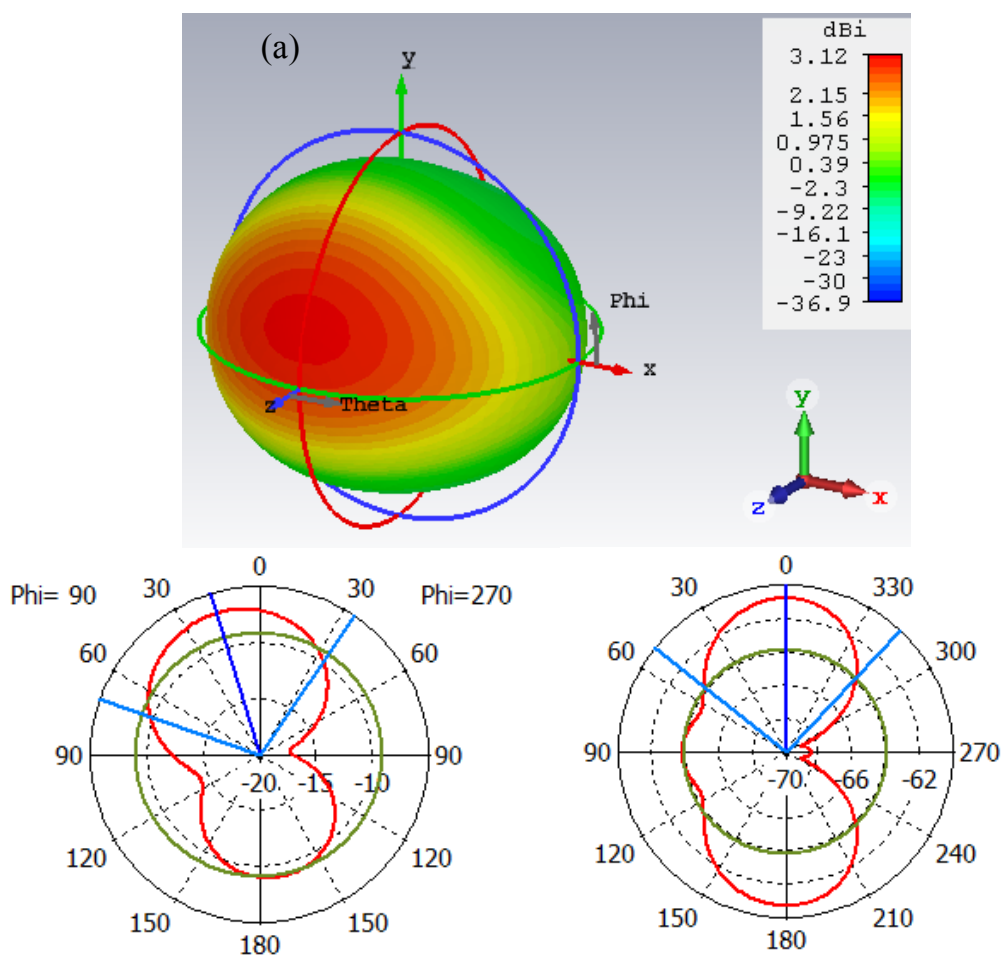

Theta/Degree vs. $\mathrm{dB} / \mathrm{m}$

(b)

Fig. 10. General 3D radiation pattern observed for the second-order structure at $1.913 \mathrm{THz}$ (a), and its cross sections by the E-plane $\left(\Phi=90^{\circ}\right)$ and $\mathrm{H}$-plane $\left(\theta=90^{\circ}\right)(\mathrm{b})$.
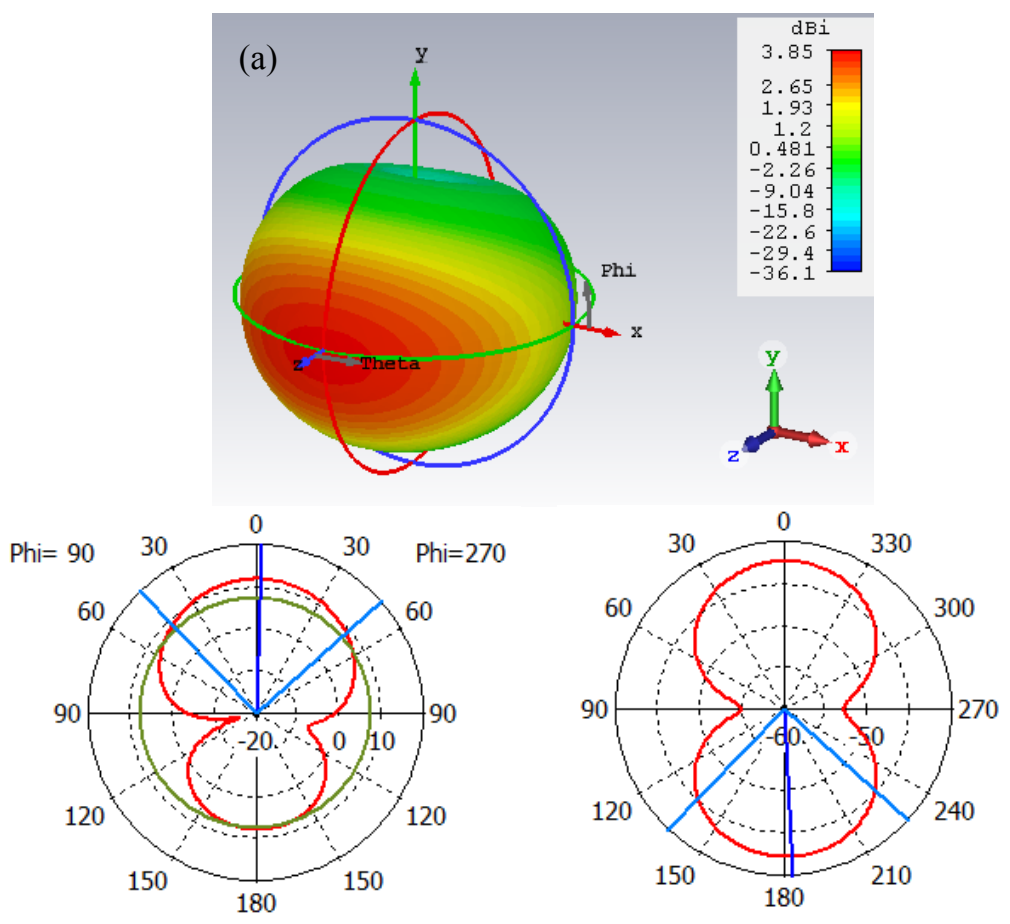

Theta/Degree vs. $\mathrm{dB} / \mathrm{m}$

(b)

Fig. 11. General 3D radiation pattern observed for the second-order structure at $3.167 \mathrm{THz}$ (a), and its cross sections by the E-plane $\left(\Phi=90^{\circ}\right)$ and $H$-plane $\left(\theta=90^{\circ}\right)(b)$.

Ukr. J. Phys. Opt. 2020, Volume 21, Issue 2 

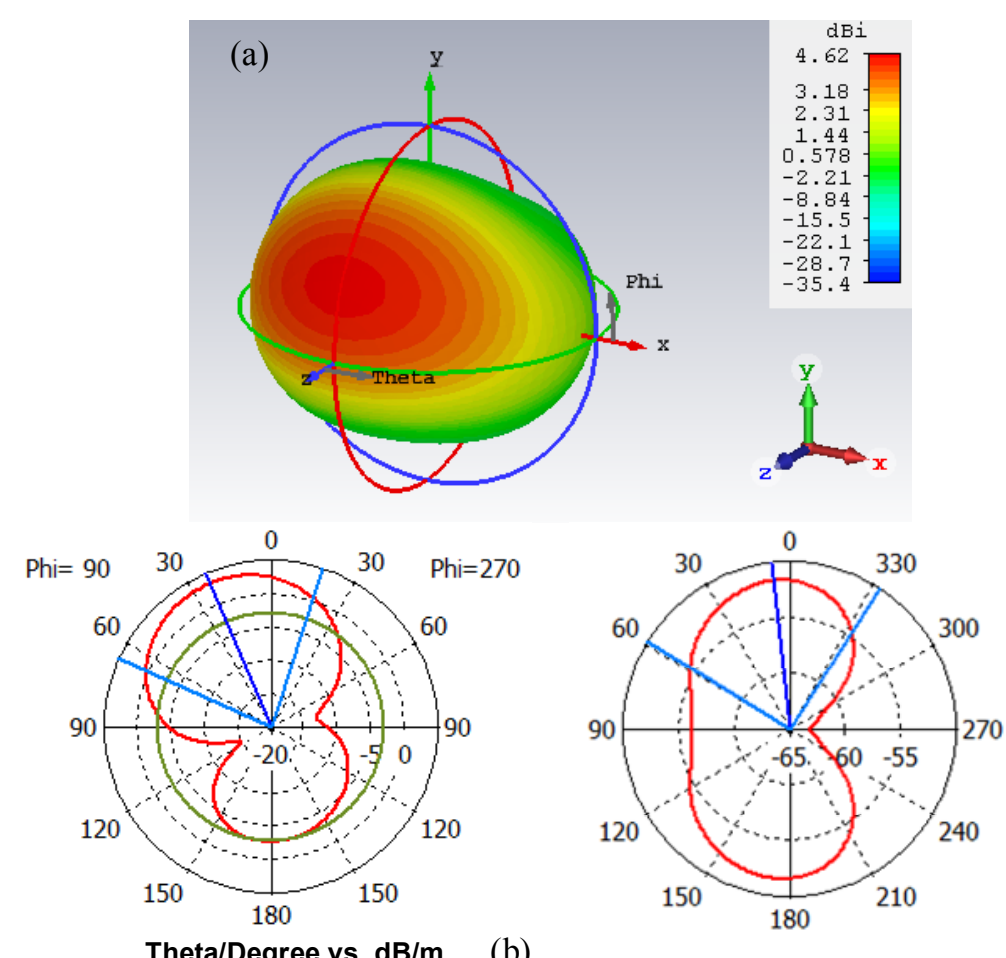

(b)

Fig. 12. General 3D radiation pattern observed for the second-order structure at $4.260 \mathrm{THz}$ (a), and its cross sections by the E-plane $\left(\Phi=90^{\circ}\right)$ and $\mathrm{H}$-plane $\left(\theta=90^{\circ}\right)(\mathrm{b})$.

Finally, Fig. 10, Fig. 11 and Fig. 12 show the whole 3D radiation pattern and its E- and Hplane cross sections for the second-order antenna structure. As with the zero- and first-order structures, the last antenna radiates mainly in the $\mathrm{Z}$ direction. The back lobes $-2.2 \mathrm{~dB}$ at $1.913 \mathrm{THz},-4.1 \mathrm{~dB}$ at $3.1672 \mathrm{THz}$ and $-6.2 \mathrm{~dB}$ at $4.26 \mathrm{THz}$ are also small. The main lobes are characterized by the angular widths $104.6^{\circ}, 92.2^{\circ}$ and $83.7^{\circ}$ respectively at $1.913,3.167$ and $4.260 \mathrm{THz}$.

While the simulation results obtained for the module of reflexion coefficient are presented in Fig. 6, Fig. 13 shows the corresponding voltage standing-wave ratios for our antennas. One can see from Fig. 6 that the antennas have a very good impedance matching with a minimal reflection loss. Table 2 gathers the main parameters for different versions of our antennas, whereas Table 3

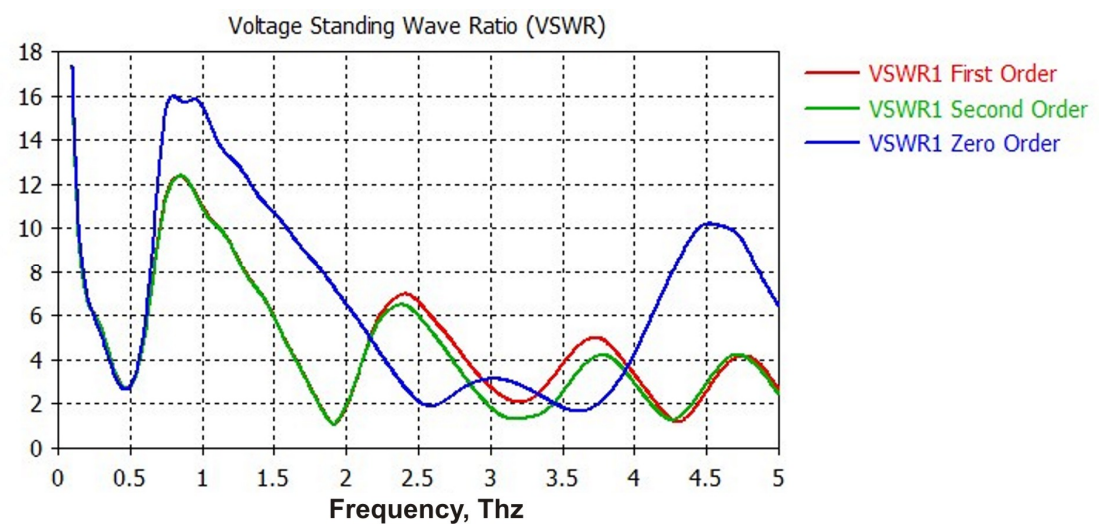

Fig. 13. Voltage standing-wave ratios for different versions of the antenna structures, as calculated at the substrate thickness $3.25 \mu \mathrm{m}$. 
makes comparison with their counterparts known from Ref. [4] in terms of the substrate thickness, the antenna size and the operating bands. Taking the data of Table 2 and Table 3 into consideration, one can see that our antennas manifest noticeable advantages over the other graphene-based terahertz antennas [4]. In particular, our design ensures a very thin substrate and good performance in terms of the number of bands, the bandwidths and the radiation patterns.

Table 2. Performance characteristics obtained for our multiband antennas of different orders.

\begin{tabular}{cccccc}
\hline $\begin{array}{c}\text { Antenna } \\
\text { structure }\end{array}$ & $\begin{array}{c}\text { Directivity } \\
\text { (decibels } \\
\text { isotropic) (dBi) }\end{array}$ & $\begin{array}{c}\text { Voltage } \\
\text { standing-wave } \\
\text { ratio }\end{array}$ & $\begin{array}{c}\text { Return loss } \\
S_{11}, \mathrm{~dB}\end{array}$ & $\begin{array}{c}\text { Frequency } \\
\text { band, } \\
\mathrm{THz}\end{array}$ & $\begin{array}{c}\text { Bandwidth } \\
\mathrm{BW}, \mathrm{GHz}\end{array}$ \\
\hline $\begin{array}{c}\text { Zero- } \\
\text { order }\end{array}$ & 4.2 & 1.646 & -12.25 & $\begin{array}{c}3.26 \\
\text { (single-band) }\end{array}$ & 260.26 \\
First- & $3.13 /$ & $1.018 /$ & $-42.18 /$ & $\begin{array}{c}1.91 / \\
4.29\end{array}$ & $186.29 /$ \\
order & 4.21 & 1.148 & -23.35 & $\begin{array}{c}\text { (dual-band) } \\
1.91 /\end{array}$ & 270.19 \\
& $3.12 /$ & $1.044 /$ & $-33.7 /$ & $3.167 /$ & $186.29 /$ \\
Second- & $3.85 /$ & $1.30 /$ & $-17.72 /$ & 4.26 & $438.75 /$ \\
order & 4.62 & 1.267 & -18.59 & (tri-band) & 264 \\
\hline
\end{tabular}

Table 3. Comparison of different parameters for our antenna and its analogues.

\begin{tabular}{cccccc}
\hline Reference & $\begin{array}{c}\text { Substrate } \\
\text { thickness, } \\
\mu \mathrm{m}\end{array}$ & $\begin{array}{c}\text { Antenna } \\
\text { size, } \\
\mu \mathrm{m}^{2}\end{array}$ & $\begin{array}{c}\text { Total } \\
\text { antenna area, } \\
\mu \mathrm{m}^{2}\end{array}$ & $\begin{array}{c}\text { Frequency } \\
\text { band, THz }\end{array}$ & $\begin{array}{c}\text { Number of } \\
\text { frequency bands }\end{array}$ \\
\hline $\begin{array}{c}\text { Ref. [4] } \\
\begin{array}{c}\text { This work (first } \\
\text { order) }\end{array}\end{array}$ & 35 & $10 \times 10$ & 100 & $2.48 / 3.35$ & $\begin{array}{c}\text { Dual-band } \\
\begin{array}{c}\text { This work } \\
\text { (second order) }\end{array}\end{array}$ \\
\hline
\end{tabular}

\section{Conclusion}

We have studied theoretically a number of new graphene-based antennas, which ensure multiband resonances in the lower terahertz region $(1-5 \mathrm{THz})$. Our antennas are characterized by a wide frequency band and compact dimensions. As seen from the simulation results obtained in the present work, our antennas manifest notable advantages over their prototypes, while the dimensions of our structures are the smallest.

\section{References}

1. Geim A K and Novoselov K S, 2007. The rise of graphene. Nature Mater. 6: 183-191.

2. Hanson G W, 2008. Dyadic Green's functions for an anisotropic, non-local model of biased graphene. IEEE Trans. Antennas and Propagation. 56: 747-757.

3. Ignacio Llatser, Christian Kremers, Albert Cabellos-Aparicio, Josep Miquel Jornet, Eduard Alarcón, Dmitry N Chigrin, 2012. Graphene-based nano-patch antenna for terahertz radiation. Photonics and Nanostructures - Fundamentals and Applications. 10: 353-358.

4. Jemima Nissiyah G and Ganesh Madhan M, 2017. Analysis of single band and dual band graphene based patch antenna for terahertz region. Physica E. 94: 126-131.

5. Khan Md Abdul Kaium, Towqir Ahmed Shaem and Mohammad Abdul Alim, 2019. Analysis of graphene based miniaturized terahertz patch antennas for single band and dual band operation. Optik. 194: 163012.

Ukr. J. Phys. Opt. 2020, Volume 21, Issue 2 
6. Bin Zhang, Josep Miquel Jornet, Ian F AkyildizIan F. Akyildiz, Zhi P Wu, 2019. Mutual coupling reduction for ultra-dense multi-band plasmonic nano-antenna arrays using graphenebased frequency selective surface. IEEE Access. 7: 33214-33225.

7. Bala R and Marwaha A, 2016. Characterization of graphene for performance enhancement of patch antenna in THz region. Optik. 127: 2089-2093.

8. Yanbin Luo, Qingsheng Zeng, Xin Yan, Yong Wu, Qichao Lu, Chaofan Zheng, Nan Hu, Wenqing Xie, Xia Zhang, 2019. Graphene-based multi-beam reconfigurable THz antennas. IEEE Access. 7: 30802-30808.

9. Tripathi Subodh Kumar, Mukesh Kumar and Ajay Kumar, 2019. Graphene based tunable and wideband terahertz antenna for wireless network communication. Wireless Networks. 25: 4371-4381.

10. Shalini M and Ganesh Madhan M, 2019. Design and analysis of a dual-polarized graphene based microstrip patch antenna for terahertz applications. Optik 194: 163050.

11. Yanbin Luo, Qingsheng Zeng, Xin Yan, Tao Jiang, Rongcao Yang, Jiayun Wang, Yong Wu, Qichao Lu, Xia Zhang, 2019. A graphene-based tunable negative refractive index metamaterial and its application in dynamic beam-tilting terahertz antenna. Microwave and Optical Technol. Lett. 61: 2766-2772.

12. Bafrooei Pedram M and Lotfollah Shafai, 1999. Characteristics of single-and double-layer microstrip square-ring antennas. IEEE Transactions on Antennas and Propagation. 47: 16331639 .

Zinelabiddine Mezache. 2020. Analysis of multiband graphene-based terahertz square-ring fractal antenna. Ukr.J.Phys.Opt. 21: 93 - 102 doi: 10.3116/16091833/21/2/93/2020

Анотація. Розроблено нову терагерияову смужкову антену з квадратним кільием, яка використовує дуже тонкий шар графену як випромінюючу смужку. Антена характеризується багатодіапазонною роботою і має поліпшену діаграму випромінювання за рахунок самоподібних властивостей, тобто фрактальної геометрї. Проаналізовано смужку на основі графену на квадратному кільиі, розміщеному на кремнієвій підкладиі завтовшки в 3,25 мкм. Структура має компактні розміри $і$ випромінює на одній частоті 3,62 ТГи. Антена також може складатися з мікросмужкової лінії, яка резонує на двох (1.913 і 4.294 ТГи) або на трьох частотах (1.913, 3.167 і 4.260 ТГи). Це досягають шляхом зміни форми смужки при коефіцієнті стоячої хвилі за напругою, меншому або рівному двійці. Розрахунки виконано в рамках повнохвильового електромагнітного моделювання на основі стандартного методу скінченних різниць у часовій області. Для режсму багатосмугової роботи визначено такі параметри як втрати повернення, коефіцієнт стоячої хвилі за напругою, підсилення та ефективність. 